in vivo $36: 713-722(2022)$

doi:10.21873/invivo.12757

\title{
Tremella fuciformis Inhibits Melanogenesis in B16F10 Cells and Promotes Migration of Human Fibroblasts and Keratinocytes
}

\author{
JO-HUA CHIANG ${ }^{1}$, FUU-JEN TSAI ${ }^{2,3}$, TSAI-HSIU LIN ${ }^{4,5}$, JAI-SING YANG $^{6}$ and YU-JEN CHIU $7,8,9$ \\ ${ }^{1}$ Department of Nursing, Chung-Jen Junior College of Nursing, \\ Health Sciences and Management, Chiayi, Taiwan, R.O.C.; \\ ${ }^{2}$ School of Chinese Medicine, College of Chinese Medicine, China Medical University, Taichung, Taiwan, R.O.C.; \\ ${ }^{3}$ Department of Medical Genetics, China Medical University Hospital, Taichung, Taiwan, R.O.C., \\ ${ }^{4}$ Department of Laboratory Medicine, Division of Molecular Diagnosis, \\ China Medical University Hospital, Taichung, Taiwan, R.O.C.; \\ ${ }^{5}$ Department of Medical Laboratory Science and Biotechnology, \\ China Medical University, Taichung, Taiwan, R.O.C.; \\ ${ }^{6}$ Department of Medical Research, China Medical University Hospital, \\ China Medical University, Taichung, Taiwan, R.O.C.; \\ ${ }^{7}$ Division of Plastic and Reconstructive Surgery, Department of Surgery, \\ Taipei Veterans General Hospital, Taipei, Taiwan, R.O.C.; \\ ${ }^{8}$ Department of Surgery, School of Medicine, National Yang Ming Chiao Tung University, Taipei, Taiwan, R.O.C.; \\ ${ }^{9}$ Institute of Clinical Medicine, National Yang Ming Chiao Tung University, Taipei, Taiwan, R.O.C.
}

\begin{abstract}
Background/Aim: Natural skin whiteners have been investigated for centuries. The development of preparations that safely achieve whitening of hyperpigmented skin lesions is a challenge for the cosmetics industry. Furthermore, promoting rapid wound healing and minimizing inflammation in injured skin are key to prevent from abnormal pigmentation in scar tissue. Natural products, including the fungus Tremella fuciformis (TF), are attracting attention as potential sources of lead compounds for these applications. Materials and Methods: We investigated the in vitro effects of TF on melanogenesis in murine B16F10 cells. Melanin and tyrosinase levels were
\end{abstract}

This article is freely accessible online.

Correspondence to: Dr. Yu-Jen Chiu, Division of Plastic and Reconstructive Surgery, Department of Surgery, Taipei Veterans General Hospital. No.201, Sec. 2, Shipai Rd., Beitou District, Taipei City 112201, Taiwan, R.O.C. Tel: +886 228757542, e-mail: chiou70202@gmail.com; Dr. Jai-Sing Yang,Department of Medical Research, China Medical University Hospital, China Medical University, No. 2, Yude Road, Taichung City 404332, Taiwan, R.O.C. Tel: +886 422052121 ext 4125, e-mail: jaisingyang@ gmail.com

Key Words: Tremella fuciformis (TF), melanogenesis, melanin, tyrosinase, wound healing. measured after treatment with TF. Wound healing in human keratinocytes (HaCaT) and fibroblasts (Detroit 551) was also determined via cell migration assay prior to TF exposure. Results: TF significantly decreased melanin content and tyrosinase expression in a concentrationdependent manner in B16F10 cells. Furthermore, TF promoted wound healing in human HaCaT keratinocytes and Detroit 551 fibroblasts. Conclusion: TF proved effectively on inhibiting melanogenesis and promoting wound healing in vitro, demonstrating its potential as a novel skin-whitening agent. However, further clinical studies of safety and efficacy are required.

Many people equate a light complexion to youth and beauty (1). Although a bronze tan is being increasingly recognized as a desirable trait in some Western countries, there is a greater overall interest in skin whitening, especially in Eastern countries. The search for safe and effective natural skin whiteners has persisted for centuries (2).

Melanin, a group of natural pigments found in most organisms, is produced by epidermal melanocytes. It is a major determinant of skin color and protects against ultraviolet (UV) irradiation (3). Melanogenesis is a multistage chemical process, involving tyrosinase and tyrosinase-related proteins, and the oxidation and polymerization of the amino acid-tyrosine (4). Tyrosinase, the rate-limiting enzyme in melanogenesis, 
A

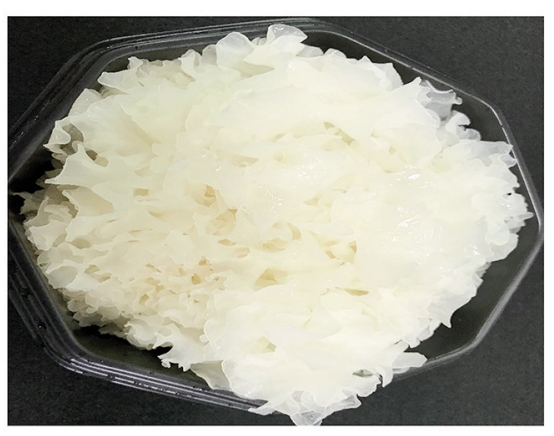

B

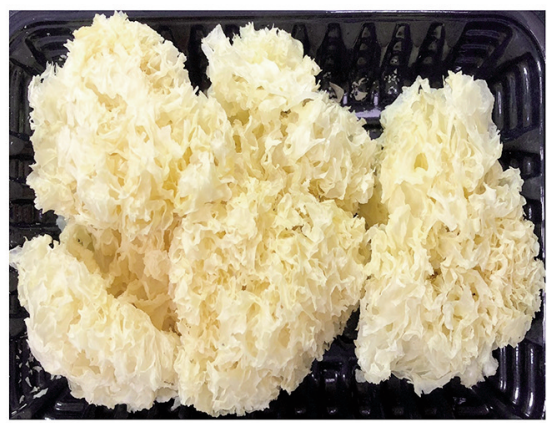

C

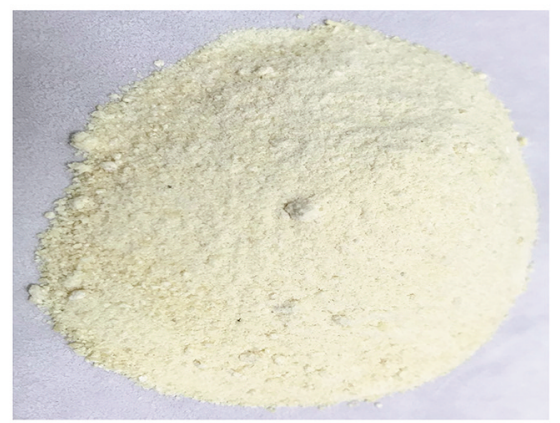

Figure 1. Gross view (A) and dry preserved T. fuciformis (TF) (B). A typical powder for medicinal use (C).

catalyzes two critical steps in melanin production (5). Numerous studies have reported that the inhibition of melanogenesis prevents skin tanning and hyperpigmentation (6). In addition, the management of cutaneous injury and scarring has long been a challenge for plastic surgeons and dermatologists. An inflammatory response is induced by cutaneous injuries $(1,7)$. Melanocytes and their production by melanogenesis are influenced by important cellular mediators in various ways. Increased inflammation in skin lesions results in increased and prolonged activation of melanogenesis, which may lead to uncontrolled melanocyte proliferation and melanoma $(7,8)$. Furthermore, skin injury with disruption to normal melanogenesis causes dyspigmentation (9). Consequently, substantial research effort is directed toward promoting rapid wound healing and minimizing inflammation in injured skin to prevent pigmentation abnormalities of the resulting scar tissue $(10,11)$.

Mercury has historically been used as a key ingredient in skin-lightening products. However, the health hazards of mercury resulted in its elimination from skin-lightening products in many countries in recent decades (12-14). The use of other hazardous chemicals, such as hydroquinone in skinlightening products, have also raised public concern about their dangers to health and emphasizes the importance of government regulations $(15,16)$. Therefore, the development of preparations that can safely achieve whitening and bleaching of hyper-pigmented lesions is a major challenge for the cosmetics industry. Natural products are attracting considerable attention as potential sources of lead compounds and drug candidates (17-20). The plant sources of such natural products are generally also established herbal medicines and dietary foods (21).

The fungus, Tremella fuciformis (TF) (Figure 1A), commonly known as white auricularia, snow fungus, snow ear, white jelly mushroom, and silver ear fungus, occurs widely, especially in tropical areas $(22,23)$. It can be found growing on the dead branches of broadleaf trees; however, TF is commercially cultivated and popularly used in cuisine and herbal medicine $(24,25)$. TF is commonly preserved as drying mushroom (Figure 1B) and processed into powder for medicinal use (Figure 1C). TF is rich in proteins, polysaccharides, and dietary fiber but low in energy and lipid content $(26,27)$. Various bioactivities have been attributed to TF, including immunomodulation, anti-oxidation, antihyperglycemia, anti-hypercholesterolemia, anti-tumor, antiaging, and helping with memory impairment (28). However, to the best of our knowledge, no study has been reported for the effects of TF on skin lightening and wound healing in vitro. The goal of this study was to investigate the in vitro effects of $\mathrm{TF}$ on the B16F10 murine melanoma cell line as well as human HaCaT keratinocytes and Detroit 551 fibroblasts.

\section{Materials and Methods}

Chemicals. Dried and preserved TF was pulverized as previously described (29). Dulbecco's modified Eagle's medium (DMEM), Minimum essential medium (MEM), fetal bovine serum (FBS), trypsin-EDTA, L-glutamine, penicillin $\mathrm{G}$, and streptomycin were purchased from Thermo Fisher Scientific (Waltham, MA, USA). The primary antibodies (against tyrosinase and $\beta$-actin) and antirabbit immunoglobulin IgG HRP-linked secondary antibodies were purchased from GeneTex International Corporation (Hsinchu, Taiwan, ROC). All other chemicals were purchased from SigmaAldrich, Merck KGaA (Darmstadt, Germany).

Cell culture. B16F10 (a murine melanoma cell line from a C57BL/6J mouse) and Detroit 551 (a human fibroblast cell line) were purchased from the Bioresource Collection and Research Center (Hsinchu, Taiwan, ROC). HaCaT, a human keratinocyte cell line, was obtained from CLS Cell Lines Service GmbH (Eppelheim, Germany). B16F10 and HaCaT cells were individually cultured in DMEM supplemented with $10 \%$ FBS, $1 \%$ penicillin-streptomycin (100 Units/ml penicillin $\mathrm{G}$ and $100 \mu \mathrm{g} / \mathrm{ml}$ streptomycin), and $2 \mathrm{mM}$ L-glutamine in a humidified atmosphere at $37^{\circ} \mathrm{C}$ in $5 \% \mathrm{CO}_{2}$. Detroit 551 cells were cultured at $37^{\circ} \mathrm{C}$ in $75 \mathrm{~cm}^{2}$ culture flasks with $10 \%$ FBS, 90\% MEM, 100 Units $/ \mathrm{ml}$ penicillin G, and $100 \mu \mathrm{g} / \mathrm{ml}$ streptomycin in a humidified $5 \% \mathrm{CO}_{2}$ atmosphere. 


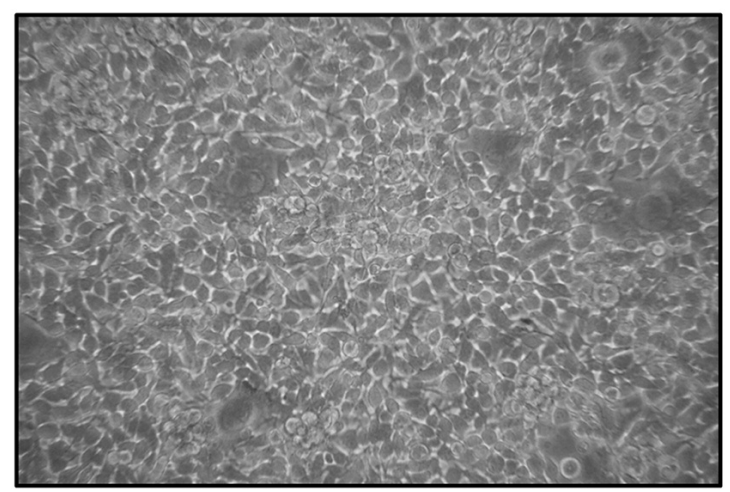

Control

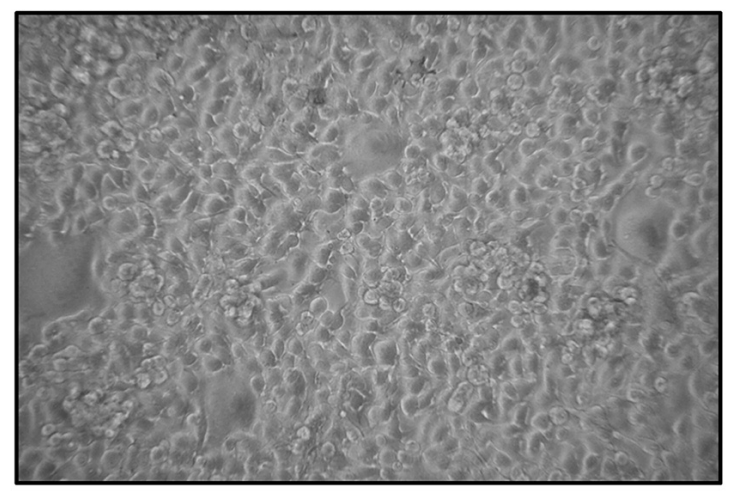

Tremella fuciformis $(50 \mu \mathrm{g} / \mathrm{ml})$

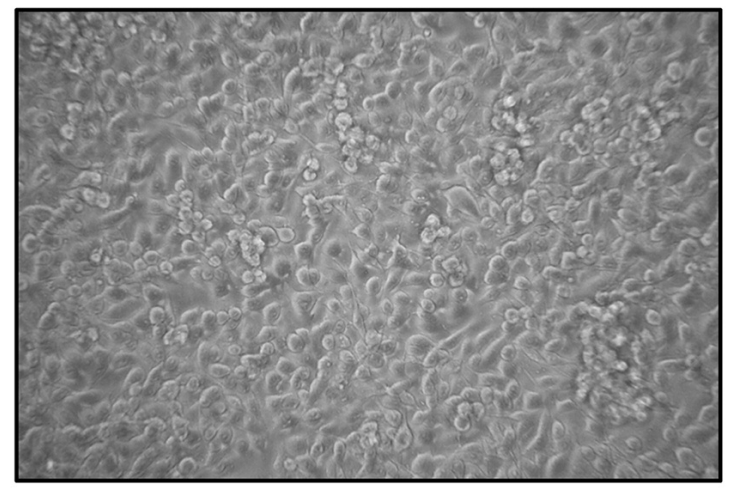

Tremella fuciformis $(200 \mu \mathrm{g} / \mathrm{ml})$

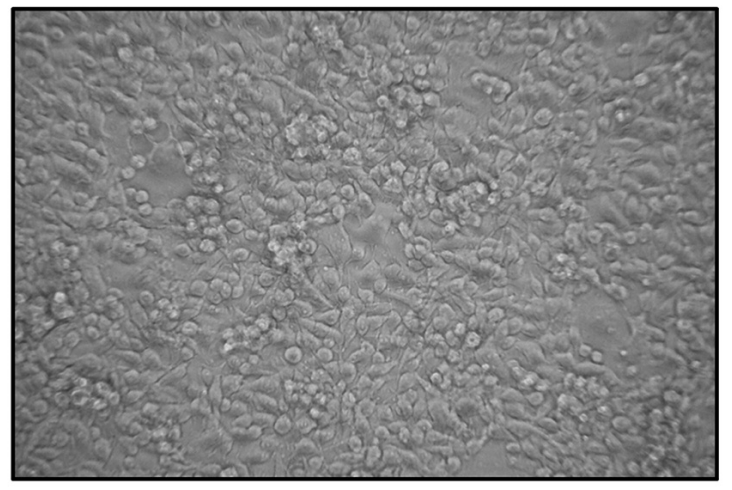

Tremella fuciformis $(100 \mu \mathrm{g} / \mathrm{ml})$

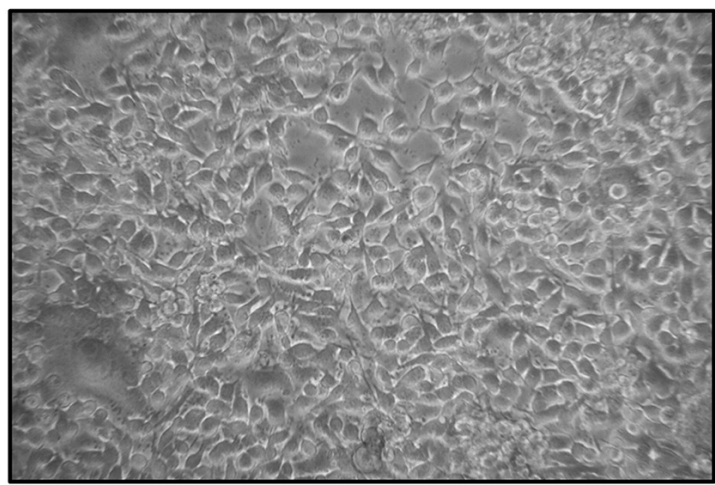

Tremella fuciformis $(300 \mu \mathrm{g} / \mathrm{ml})$

Figure 2. Effects of different concentrations of T. fuciformis (TF) (50,100, 200, and $300 \mu \mathrm{g} / \mathrm{ml})$ on B16F10 murine melanoma cell morphology. Cell images were obtained via a phase-contrast microscope at $\times 200$ magnification.

Morphology and cell viability assays. B16F10 cells were seeded in a 96-well plate at an initial density of $1 \times 10^{4}$ cells $/ 100 \mu$ l. The cells were incubated at $37^{\circ} \mathrm{C}$ with or without different concentrations of $\mathrm{TF}(50,100,200$, and $300 \mu \mathrm{g} / \mathrm{ml})$ for $24 \mathrm{~h}$. Cell images were then photographed via a phase-contrast microscope at $\times 200$ magnification (Leica Microsystems GmbH, Wetzlar, Germany) After that, addition of 3-(4,5-dimethylthiazol-2-yl)-2,5diphenyltetrazolium bromide (MTT) solution $(0.5 \mathrm{mg} / \mathrm{ml})$ was added to each well before further incubation at $37^{\circ} \mathrm{C}$ for $4 \mathrm{~h}$. Subsequently, the culture medium was removed, and the formazan crystals were dissolved with $100 \mu$ l dimethyl sulfoxide (DMSO) in isopropanol. Absorbance was measured spectrophotometrically at $570 \mathrm{~nm}$ via SpectraMax iD3 multimode microplate reader (Molecular Devices Ltd., San Jose, CA, USA). The cell survival ratio was expressed as a percentage of the control, as previously described (30). 


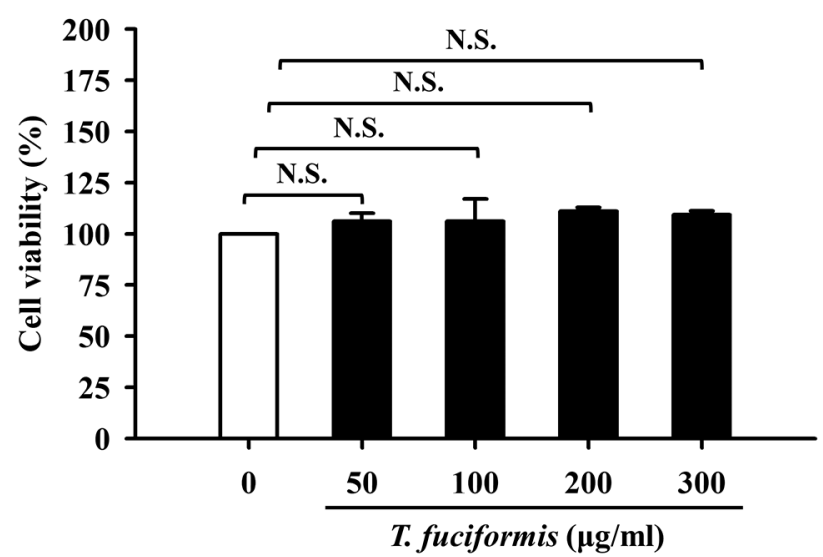

Figure 3. Effects of different concentrations (50, 100, 200, and 300 $\mu \mathrm{g} / \mathrm{ml}$ ) of T. fuciformis (TF) on B16F10 murine melanoma cell viability. The results shown are the averages of triplicate experiments \pm standard deviation. N.S.: Not significant.

Melanin measurement. B16F10 cells $\left(1 \times 10^{4}\right.$ cells/100 $\left.\mu \mathrm{l}\right)$ were placed in a 96-well cell culture plate, and allowed to attach overnight at $37^{\circ} \mathrm{C}$. The cells were exposed to different concentrations of TF $(50,100,200$, and $300 \mu \mathrm{g} / \mathrm{ml})$ for $48 \mathrm{~h}$ at $37^{\circ} \mathrm{C}$, and then incubated for an additional $24 \mathrm{~h}$ in the presence or absence of $0.5 \mu \mathrm{M} \alpha$-melanocyte stimulating hormone $(\alpha-\mathrm{MSH})$ (Sigma-Aldrich). The cells were subsequently washed twice with PBS, and lysed for $1 \mathrm{~h}$ at $90^{\circ} \mathrm{C}$ in $1 \mathrm{M} \mathrm{NaOH}$ containing $10 \%$ DMSO. The total melanin in each cell suspension was determined by measuring the absorbance at $405 \mathrm{~nm}$ using a spectrophotometric multi-plate reader (SpectraMax iD3 multimode microplate reader, Molecular Devices Ltd.). The melanin content of the TF-treated cells was expressed as a percentage of the untreated cells. The total melanin content was determined according to a previously described method (31), with slight modifications.

Western blot analysis. B16F10 cells $\left(5 \times 10^{6}\right.$ cells per $75 \mathrm{~T}$ flask $)$ were incubated at $37^{\circ} \mathrm{C}$ with $\mathrm{TF}$ at different concentrations $(100,200$, and $300 \mu \mathrm{g} / \mathrm{ml}$ ) for $24 \mathrm{~h}$ before exposure to $0.5 \mu \mathrm{M} \alpha-\mathrm{MSH}$ for an additional $24 \mathrm{~h}$. Cell samples were lysed in Trident RIPA Lysis Buffer (GeneTex). Protein concentrations were determined using a Pierce BCA Protein Assay Kit (Thermo Fisher Scientific). Equal amounts of the protein sample $(40 \mu \mathrm{g})$ were prepared and loaded onto $10 \%$ sodium dodecyl sulfate-polyacrylamide gels $(32,33)$. Proteins were then transferred to an Immobilon-P polyvinylidene difluoride transfer membrane (Merck KGaA, Darmstadt, Germany) prior to blocking with 5\% skim milk for $1 \mathrm{~h}$ at room temperature. The membrane was subsequently incubated overnight at $4^{\circ} \mathrm{C}$ with primary antibodies against tyrosinase and $\beta$-actin at a dilution of 1:1,000. Membranes were then incubated for $1 \mathrm{~h}$ at $25^{\circ} \mathrm{C}$ with an anti-rabbit $\operatorname{IgG}$ horseradish peroxidase (HRP)-linked secondary antibody at a dilution of 1:10,000. Blot visualization was performed using the Immobilon Western Chemiluminescent HRP Substrate (Merck $\mathrm{KGaA}$ ), and all bands of immunoblots were normalized to the densitometric value of $\beta$-actin. The bands were quantified by densitometry using ImageJ software (version 1.41; National Institutes of Health, Bethesda, MA, USA) $(34,35)$.

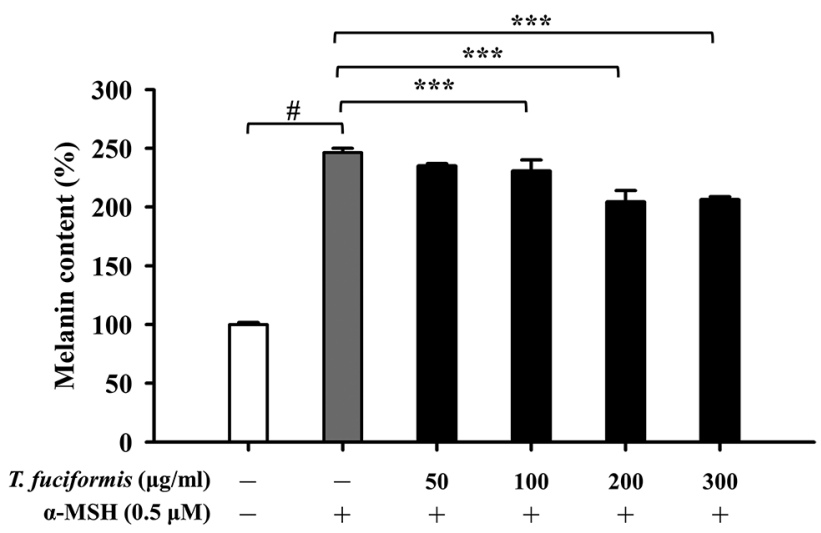

Figure 4. Effects of different concentrations of T. fuciformis $(T F)$ on melanin content in B16F10 murine melanoma cells. The cells were exposed to TF $(50,100,200$, and $300 \mu \mathrm{g} / \mathrm{ml})$ for $48 \mathrm{~h}$, followed by 24 $h$ incubation with or without $0.5 \mu M \alpha$-melanocyte-stimulating hormone $(\alpha-M S H)$. The results shown are the averages of triplicate experiments \pm standard deviation. ${ }^{\#} p<0.05 v s$. the $\alpha-M S H$-untreated control group. $*^{* *} p<0.001 \mathrm{vs.} \alpha$-MSH-treated control.

\section{T. fuciformis $(\mu \mathrm{g} / \mathrm{ml}) \quad-\quad-\quad \begin{array}{llll}100 & 200 & 300\end{array}$ $\alpha$-MSH $(0.5 \mu \mathrm{M}) \quad-\quad+\quad+\quad+\quad+$ Tyrosinase $=-\infty-\infty-$ $\begin{array}{lllll}1.0 & 2.3 & 1.7 & 0.8 & 0.5\end{array}$ \\ $\beta$-Actin}

Figure 5. Effects of different concentrations of T. fuciformis (TF) on tyrosinase expression in B16F10 murine melanoma cells. The cells were exposed to TF (100, 200, and $300 \mu \mathrm{g} / \mathrm{ml})$ for $48 \mathrm{~h}$, followed by $24 \mathrm{~h}$ incubation with or without $0.5 \mu \mathrm{M} \alpha$-melanocyte-stimulating hormone $(\alpha-M S H)$. Tyrosinase protein levels were detected via western blot. $\beta$ Actin was to ensure equal loading.

Dynamic wound healing assay. HaCaT cells $\left(1 \times 10^{4}\right.$ cells/well) into a 96-well plate overnight were scratched using Incucyte 96-Well Woundmaker Tool (Essen BioScience, Ann Arbor, MI, USA) and then treated with or without 100 and $200 \mu \mathrm{g} / \mathrm{ml} \mathrm{TF}$ in serum-free DMEM. The cell migration images and wound width were recorded over 12 $\mathrm{h}$ with data collection every $30 \mathrm{~min}$ and monitored using Incucyte S3 Live-Cell Analysis System and Incucyte Scratch Wound Analysis Software Module (Essen BioScience), as previously described (36).

Cell migration assay. Detroit 551 cells were transferred to a 6-well tissue culture plate for $24 \mathrm{~h}$, and the cells were grown up to $90 \%$ confluence. Subsequently, each well was scratched with a micropipette tip to create a denuded zone of constant width $(1 \mathrm{~mm})$. The cells were then cultured in serum-free MEM and incubated at $37^{\circ} \mathrm{C}$ with different concentrations of $\mathrm{TF}(100$, and $200 \mu \mathrm{g} / \mathrm{ml})$ for $24 \mathrm{~h}$. The cells and the denuded zones were photographed under phase-contrast microscopy $(\times 100)$, as previously described $(34,37)$.

Statistical analysis. All data are presented as the mean \pm standard deviation of three separate experiments. One-way analysis of 


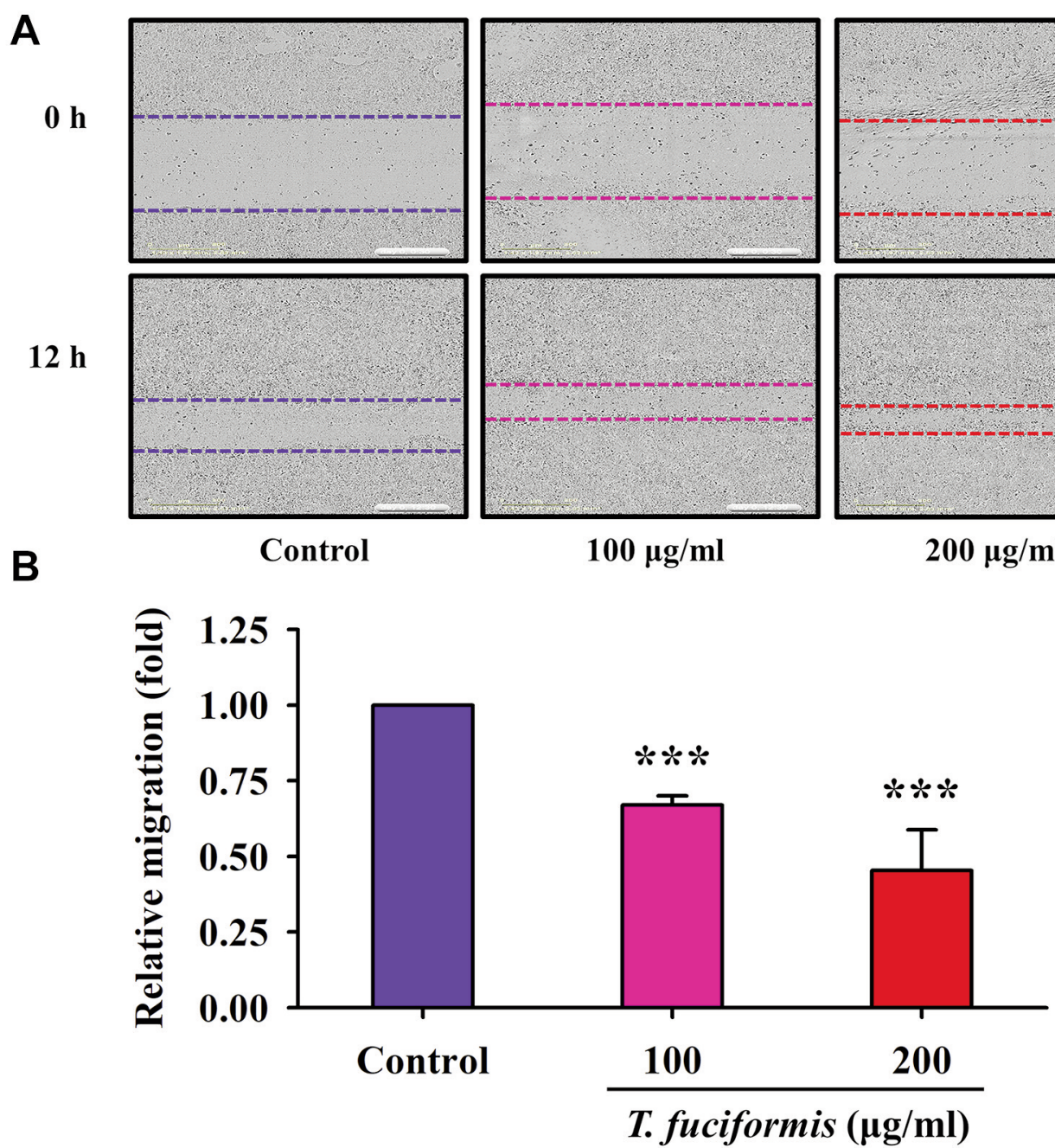

Figure 6. Effects of different concentrations of T. fuciformis (TF) (100, and $200 \mu \mathrm{g} / \mathrm{ml})$ on wound healing in human keratinocytes (HaCaT cell line). The cells were photographed $(A)$, and cell migration $(B)$ was quantified. The results shown are the averages of triplicate experiments \pm standard deviation. $* * * p<0.001$ vs. the control group.

variance followed by Dunnett's test was conducted to analyze the differences between groups and multiple comparisons (SPSS software version 26.0, Chicago, IL, USA). The statistical significance was set at $p<0.05$ or $p<0.001$.

\section{Results}

In vitro proliferation of murine melanoma B16F10 cells was unaffected by TF concentrations of up to $300 \mu \mathrm{g} / \mathrm{ml}$. The cells were treated with various concentrations of TF $(50$, 100,200 , and $300 \mu \mathrm{g} / \mathrm{ml}$ ) and analyzed using the MTT cell viability assay. TF treatment did not induce any changes in cell morphology (Figure 2), and no significant effect of the number of viable B16F10 cells was found when compared with untreated cells (Figure 3). Therefore, treatment with TF at the highest tested concentration of $300 \mu \mathrm{g} / \mathrm{ml}$ was suitable for subsequent evaluation in the melanin synthesis and tyrosinase activity.

TF decreased melanin content and tyrosinase levels in B16F10 cells. Melanin production is a multistage chemical process involving tyrosinase and tyrosinase-related proteins $(5,38)$. We measured the melanin content of B16F10 cells (Figure 4), which exhibited a concentration-dependent decreasing trend in response to TF treatment. Significant reductions in melanin content were observed in the 100,200 , and $300 \mu \mathrm{g} / \mathrm{ml}$ of TF treatment groups compared with the $\alpha$-MSH-treated group. Tyrosinase is the rate-limiting enzyme in melanogenesis and catalyzes two critical steps (39). Therefore, we further evaluated the tyrosinase levels in B16F10 cells after TF treatment at 100 , 200 , and $300 \mu \mathrm{g} / \mathrm{ml}$, showing that tyrosinase expression was decreased in a concentration-dependent manner (Figure 5). 


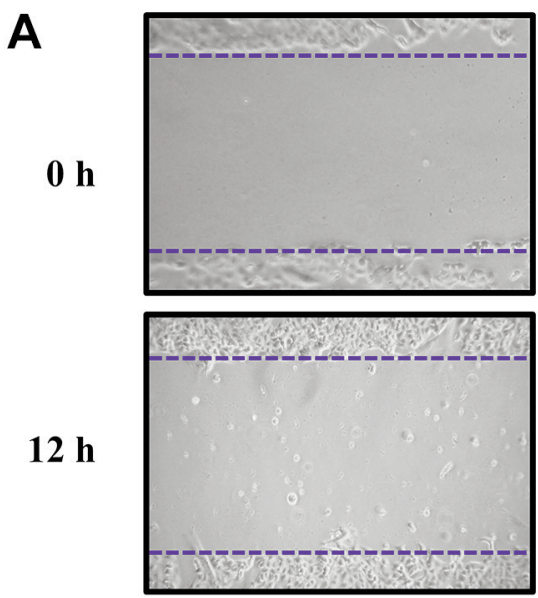

B

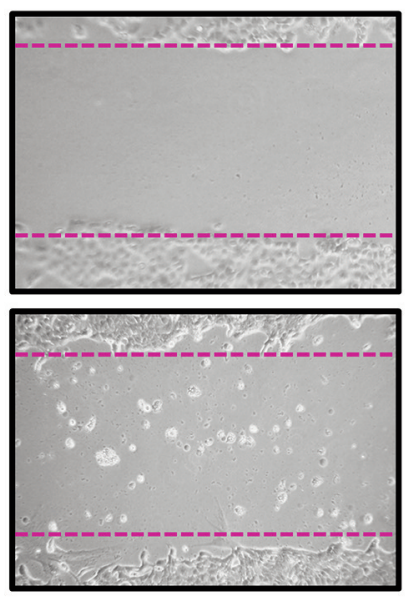

$100 \mu \mathrm{g} / \mathrm{ml}$

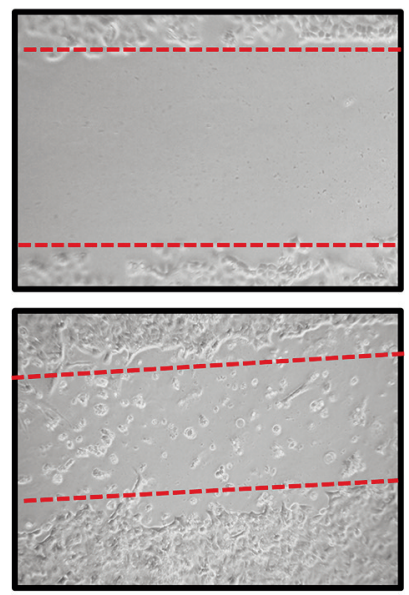

$200 \mu \mathrm{g} / \mathrm{ml}$

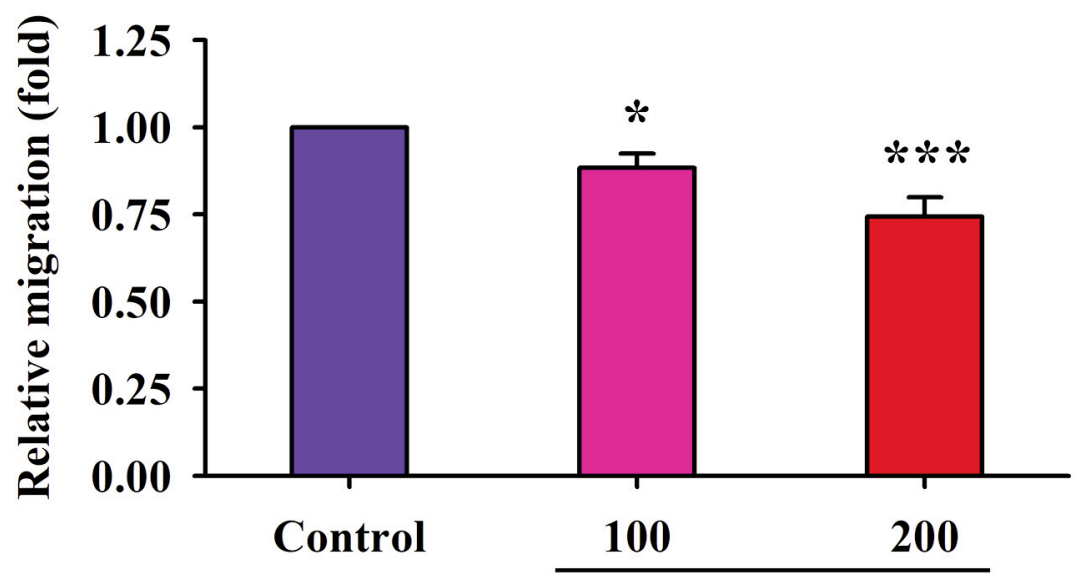

T. fuciformis $(\mu \mathrm{g} / \mathrm{ml})$

Figure 7. Effects of different concentrations of T. fuciformis (TF) (100, and $200 \mu \mathrm{g} / \mathrm{ml})$ on cell migration in human skin fibroblasts (Detroit 551 cells). The cells were photographed (A), and cell migration $(B)$ was quantified. The results shown are the averages of triplicate experiments \pm standard deviation. ${ }^{*} p<0.05$ and $* * * p<0.001$ vs. the control group.

TF promoted cell motility in human keratinocytes (HaCaT) and human skin fibroblasts (Detroit 551). Previous studies have reported that rapid wound healing prevents from abnormalities of pigmentation and hyperpigmentation (40). Thus, we treated human keratinocyte HaCaT cells and human fibroblast Detroit 551 cells with different concentrations of TF $(100$ and $200 \mu \mathrm{g} / \mathrm{ml})$ to evaluate cell migration using a wound-healing assay. The results for $\mathrm{HaCaT}$ and Detroit 551 cells (Figure 6 and Figure 7, respectively), revealed that the edge distances in the TF treatment groups were significantly shorter than that in the control group. Furthermore, the dynamic observation via Incucyte S3 Live-Cell Analysis System also showed that the wound was closing progressively after incubation with or without TF (100 and $200 \mu \mathrm{g} / \mathrm{ml})$ in $\mathrm{HaCaT}$ cells (supplementary video, available at: https://youtu.be/4uYg3wg710g). Therefore, TF promoted both
HaCaT and Detroit 551 cell migration in a concentrationdependent manner.

\section{Discussion}

Natural skin whitening has been explored for centuries because of its cultural associations with the youth and beauty (41). Mercury-containing skin lighteners were once widely used; however, their popularity declined as following their association with health hazards (12). Natural compounds are receiving significant attention as potential skin-whitening agents. To the best of our knowledge, this is the first study to report on the effects of TF on skin complexion. TF effectively reduced melanin production in $\mathrm{B} 16 \mathrm{~F} 10$ cells and promoted wound healing in human HaCaT keratinocytes and Detroit 551 fibroblasts. 


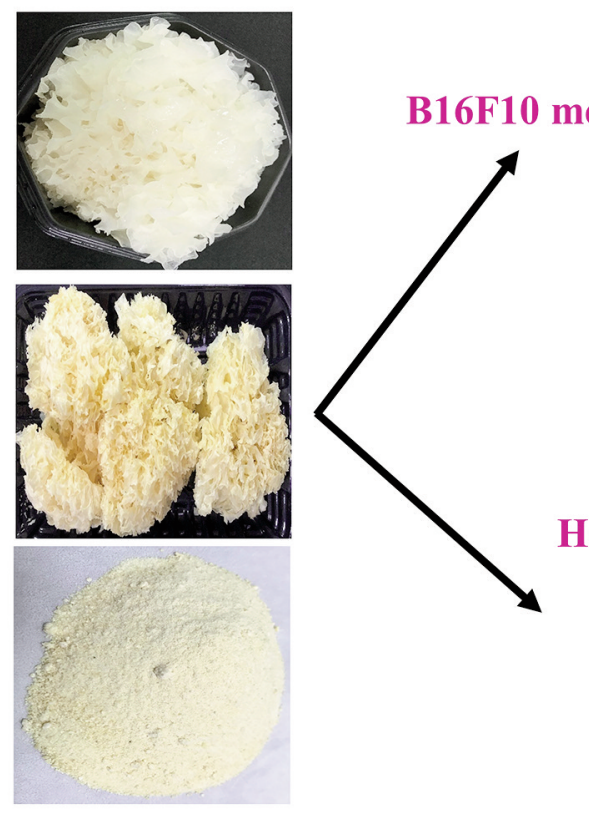

HaCaT keratinocytes

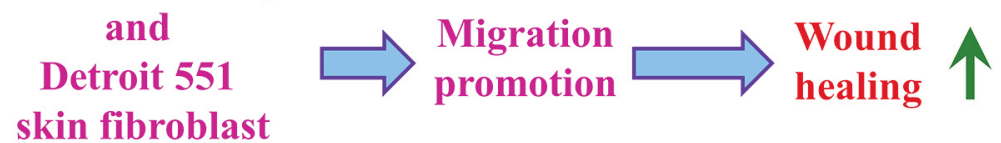

\section{T. fuciformis}

Figure 8. Summarized in vitro effects of Tremella fuciformis $(T F)$ on skin whitening and wound healing in the present study.

Melanin is produced by epidermal melanocytes, which are the main determinants of skin color (42). Interestingly, skin color and pigmentation are not determined by the number of melanocytes within the epidermis and dermis, but rather by the activity of melanocytes (43). Staricco et al. (44, 45) reported that there was no significant difference in the number of melanocytes between black and white-skinned individuals. Within a particular individual, the highest numbers of melanocytes typically occur in the head, neck, limbs, and genitalia, and the lowest numbers on the chest and abdomen (44, 45). Iozumi et al. (46) subsequently demonstrated that tyrosinase levels and activity determine pigmentation in cultured human melanocytes. The ratelimiting enzyme, tyrosinase, catalyzes two critical steps in melanin production, namely the hydroxylation of L-tyrosine to form L-dihydroxyphenylalanine (L-DOPA), and the oxidation of L-DOPA into the corresponding dopaquinone (47). The inhibition of melanogenesis has been reported in many studies to prevent skin tanning and hyperpigmentation (6). B16F10, a mouse melanoma cell line, is known to have stable melanin production, and that is an excellent cellular model for evaluating melanogenic effects $(48,49)$. TF treatment neither induced any changes in cell morphology (Figure 2) nor significantly affected B16F10 cell viability (Figure 3). Furthermore, melanin content (Figure 4) and tyrosinase expression (Figure 5) in B16F10 cells were decreased in a concentration-dependent manner as a result of treatment with TF.
Skin injury disrupts normal melanogenesis, resulting in dyspigmentation, which has long been a challenge for plastic surgeons and dermatologists (50). Wound healing following skin injury is involved in three main stages: inflammation, proliferation, and remodeling (51). Excess inflammation plays a major role in impaired wound healing and the etiology of scarring. Furthermore, increased inflammation results in increased and prolonged activation of melanogenesis, leading to uncontrolled melanocyte proliferation, dyspigmentation, and melanoma $(7,8)$. Recent studies indicated that TF can modulate the body's immune functions by regulating immune cells and molecules and their activities without significant side effects (52). Shi et al. (53) reported that TF modulated $\mathrm{CD}^{+}{ }^{+} \mathrm{T}$ cell proliferation and polarization in mice with Pseudomonas aeruginosa-infected, full-thickness burn injuries, resulting in reduced levels of IL-10. The use of TF may effectively enhance immune status (54). Furthermore, TF has been shown to possess antioxidant properties and may act as a potential therapeutic agent for oxidative-stress-associated skin diseases and aging (55). Shen et al. (56) reported that TF suppressed hydrogen peroxide-triggered injury in human skin fibroblasts via upregulation of SIRT1, while Wen et al. (57) reported that TF scavenged $87 \%$ and $80 \%$ of superoxide and hydroxyl radicals, respectively, in a rat model of UV-induced skin damage.

In the proliferation stage of wound healing, greater numbers of keratinocytes and fibroblasts proliferate and migrate to wound margins, thereby promoting wound formation (58). A previous study reported that $\mathrm{TF}$ pretreatment reduced 
oxidative stress and cell apoptosis in hydrogen peroxidetreated skin fibroblasts. Moreover, it was also shown that TF inhibited p16, p21, p53, and caspase-3 expression, and activated extracellular signal-regulated kinase and Akt serine/threonine kinase 1 (59). To the best of our knowledge, no study has discussed the effects of TF on wound healing. Herein, we showed that TF significantly promoted wound healing in human HaCaT keratinocytes (Figure 6) and human Detroit 551 fibroblasts (Figure 7). Promoting rapid wound healing and minimizing the inflammatory process in injured skin are key factors in preventing pigmentation abnormalities of the resulting scar (60).

In summary, we are the first to report the effects of $\mathrm{TF}$ on melanogenesis and the promotion of wound healing (Figure 8). TF significantly reduced melanin production and tyrosinase protein levels in B16F10 cells; TF also effectively promoted the migration of human keratinocytes and fibroblasts. Our data suggest that TF may prove useful as a novel skin-whitening candidate in the future. Further clinical studies are required to assess the safety and efficacy of TF in the near future.

\section{Funding}

The Authors are grateful for the financial support provided by the China Medical University Hospital (grant no. DMR-106-179), Taipei Veterans General Hospital (grant no. V110B-038), and Chung-Jen Junior College of Nursing, Health Sciences and Management (grant no. 110-002).

\section{Conflicts of Interest}

The Authors declare that they have no competing interests in relation to this study.

\section{Authors' Contributions}

Conceptualization and study design: JHC, JSY and YJC. Cell migration, cell viability, western blotting and melanin content detection: JHC and FJT. Wound healing assay and acquisition of data: JHC and THL. Statistical analysis of all data and interpretation of results: JHC, FJT, THL, JSY, and YJC confirm the authenticity of all the raw data. All Authors read and approved the final manuscript.

\section{Acknowledgements}

The Authors would like to thank Mr. Chang-Wei Li (AllBio Science, Inc., Taichung, Taiwan) for his excellent technical support. The Authors would also like to acknowledge the work of Mr. KaiHsiang Chang and Mr. Chin-Chen Lin (Tekon Scientific Corporation, Taipei, Taiwan) for their assistance and equipment support on this study. We also thank the Office of Research and Development, China Medical University (Taiwan, ROC) for providing Medical Research Core Facilities to perform the experiments and data analysis.

\section{References}

1 Eassa HA, Eltokhy MA, Fayyaz HA, Khalifa MKA, Shawky S, Helal NA, Eassa HA, Youssef SF, Latz IK and Nounou MI: Current topical strategies for skin-aging and inflammaging treatment: science versus fiction. J Cosmet Sci 71(5): 321-350, 2020. PMID: 33022200.

2 Yap WN: Tocotrienol-rich fraction attenuates UV-induced inflammaging: A bench to bedside study. J Cosmet Dermatol 17(3): 555-565, 2018. PMID: 28952200. DOI: 10.1111/ jocd. 12421

3 Hollis DE and Scheibner A: Ultrastructural changes in epidermal Langerhans cells and melanocytes in response to ultraviolet irradiation, in Australians of Aboriginal and Celtic descent. Br J Dermatol 119(1): 21-31, 1988. PMID: 3408661. DOI: 10.1111/j.1365-2133.1988.tb07097.x

4 Palumbo A, Poli A, Di Cosmo A and d'Ischia M: N-Methyl-Daspartate receptor stimulation activates tyrosinase and promotes melanin synthesis in the ink gland of the cuttlefish Sepia officinalis through the nitric Oxide/cGMP signal transduction pathway. A novel possible role for glutamate as physiologic activator of melanogenesis. J Biol Chem 275(22): 16885-16890, 2000. PMID: 10748137. DOI: 10.1074/jbc.M909509199

5 Lee TH and Lee MS: Biochemistry of melanin synthesis: in vivo effects of MSH on tyrosinase and melanogenesis of pigmentary system. Yale J Biol Med 46(5): 493-499, 1973. PMID: 4205116.

6 Makino ET, Mehta RC, Banga A, Jain P, Sigler ML and Sonti S: Evaluation of a hydroquinone-free skin brightening product using in vitro inhibition of melanogenesis and clinical reduction of ultraviolet-induced hyperpigmentation. J Drugs Dermatol 12(3): s16-s20, 2013. PMID: 23545928.

7 Fu C, Chen J, Lu J, Yi L, Tong X, Kang L, Pei S, Ouyang Y, Jiang L, Ding Y, Zhao X, Li S, Yang Y, Huang J and Zeng Q: Roles of inflammation factors in melanogenesis (Review). Mol Med Rep 21(3): 1421-1430, 2020. PMID: 32016458. DOI: 10.3892/mmr.2020.10950

8 Prunieras M: Melanocytes, melanogenesis, and inflammation. Int J Dermatol 25(10): 624-628, 1986. PMID: 2433237. DOI: 10.1111/j.1365-4362.1986.tb04521.x

9 Dobos G, Trojahn C, D'Alessandro B, Patwardhan S, Canfield D, Blume-Peytavi U and Kottner J: Effects of intrinsic aging and photodamage on skin dyspigmentation: an explorative study. J Biomed Opt 21(6): 66016, 2016. PMID: 27330007. DOI: 10.1117/1.JBO.21.6.066016

10 Lee AY: Skin pigmentation abnormalities and their possible relationship with skin aging. Int J Mol Sci 22(7): 3727, 2021. PMID: 33918445. DOI: 10.3390/ijms22073727

11 Lutz W: [Abnormalities of pigmentation and skin appendices]. Dermatologica 104(6): 449-452, 1952. PMID: 14945245.

12 Dórea JG: Additional comments to "Potential health consequences of applying mercury-containing skin-lightening creams during pregnancy and lactation periods". Int J Hyg Environ Health 219(8): 920-921, 2016. PMID: 27451074. DOI: 10.1016/j.ijheh.2016.07.010

13 Al-Saleh I: Potential health consequences of applying mercurycontaining skin-lightening creams during pregnancy and lactation periods. Int J Hyg Environ Health 219(4-5): 468-474, 2016. PMID: 27009692. DOI: 10.1016/j.ijheh.2016.03.002

14 Pollock S, Taylor S, Oyerinde O, Nurmohamed S, Dlova N, Sarkar R, Galadari H, Manela-Azulay M, Chung HS, Handog E 
and Kourosh AS: The dark side of skin lightening: An international collaboration and review of a public health issue affecting dermatology. Int J Womens Dermatol 7(2): 158-164, 2020. PMID: 33937483. DOI: 10.1016/j.ijwd.2020.09.006

15 Draelos ZD, Deliencourt-Godefroy G and Lopes L: An effective hydroquinone alternative for topical skin lightening. J Cosmet Dermatol 19(12): 3258-3261, 2020. PMID: 33098161. DOI: 10.1111/jocd.13771

16 Tai Y, Wang C, Wang Z, Liang Y, Du J, He D, Fan X, Jordt SE and Liu B: Involvement of Transient Receptor Potential Cation Channel Member A1 activation in the irritation and pain response elicited by skin-lightening reagent hydroquinone. Sci Rep 7(1): 7532, 2017. PMID: 28790335. DOI: 10.1038/s41598-017-07651-5

17 Wijayasinghe YS, Bhansali P, Viola RE, Kamal MA and Poddar NK: Natural products: a rich source of antiviral drug lead candidates for the management of COVID-19. Curr Pharm Des 27(33): 3526-3550, 2021. PMID: 33213322. DOI: 10.2174/ 1381612826666201118111151

18 Ansari N and Khodagholi F: Natural products as promising drug candidates for the treatment of Alzheimer's disease: molecular mechanism aspect. Curr Neuropharmacol 11(4): 414-429, 2013 PMID: 24381531. DOI: 10.2174/1570159X11311040005

19 Kang YH, Lee HJ, Lee CJ and Park JS: Natural products as sources of novel drug candidates for the pharmacological management of osteoarthritis: a narrative review. Biomol Ther (Seoul) 27(6): 503-513, 2019. PMID: 31646842. DOI: 10.4062/ biomolther.2019.139

20 Vuorelaa P, Leinonenb M, Saikkuc P, Tammelaa P, Rauhad JP, Wennberge $\mathrm{T}$ and Vuorela $\mathrm{H}$ : Natural products in the process of finding new drug candidates. Curr Med Chem 11(11): 1375-1389, 2004. PMID: 15180572 . DOI: 10.2174/0929867043365116

21 Kolodziej H: Fascinating metabolic pools of Pelargonium sidoides and Pelargonium reniforme, traditional and phytomedicinal sources of the herbal medicine Umckaloabo. Phytomedicine 14 Suppl 6: 917, 2007. PMID: 17188477. DOI: 10.1016/j.phymed.2006.11.021

$22 \mathrm{Xu} \mathrm{X}$, Chen A, Ge X, Li S, Zhang $\mathrm{T}$ and $\mathrm{Xu} \mathrm{H}$ : Chain conformation and physicochemical properties of polysaccharide (glucuronoxylomannan) from Fruit Bodies of Tremella fuciformis. Carbohydr Polym 245: 116354, 2020. PMID: 32718589. DOI: 10.1016/j.carbpol.2020.116354

23 Li M, Ma F, Li R, Ren G, Yan D, Zhang H, Zhu X, Wu R and $\mathrm{Wu}$ J: Degradation of Tremella fuciformis polysaccharide by a combined ultrasound and hydrogen peroxide treatment: Process parameters, structural characteristics, and antioxidant activities Int J Biol Macromol 160: 979-990, 2020. PMID: 32473217. DOI: $10.1016 /$ j.ijbiomac.2020.05.216

24 Fan XZ, Yao F, Yin CM, Shi DF and Gao H: Optimization of fermentation process and its impact on gene transcription of intracellular polysaccharide synthesis in the wood ear medicinal mushroom Auricularia auricula-judae (Agaricomycetes). Int J Med Mushrooms 22(6): 581-592, 2020. PMID: 32865899. DOI: 10.1615/IntJMedMushrooms.2020035033

25 Liang CH, Wu CY, Lu PL, Kuo YC and Liang ZC: Biological efficiency and nutritional value of the culinary-medicinal mushroom Auricularia cultivated on a sawdust basal substrate supplement with different proportions of grass plants. Saudi J Biol Sci 26(2): 263-269, 2019. PMID: 31485164. DOI: 10.1016 /j.sjbs.2016.10.017

26 Zhang Y, Li X, Yang Q, Zhang C, Song X, Wang W, Jia L and Zhang J: Antioxidation, anti-hyperlipidaemia and hepatoprotection of polysaccharides from Auricularia auricular residue. Chem Biol Interact 333: 109323, 2021. PMID: 33212049. DOI: 10.1016/j.cbi.2020.109323

27 Miao J, Regenstein JM, Qiu J, Zhang J, Zhang X, Li H, Zhang $\mathrm{H}$ and Wang $\mathrm{Z}$ : Isolation, structural characterization and bioactivities of polysaccharides and its derivatives from Auricularia-A review. Int J Biol Macromol 150: 102-113, 2020. PMID: 32044370. DOI: 10.1016/j.ijbiomac.2020.02.054

$28 \mathrm{Wu}$ YJ, Wei ZX, Zhang FM, Linhardt RJ, Sun PL and Zhang AQ: Structure, bioactivities and applications of the polysaccharides from Tremella fuciformis mushroom: A review. Int J Biol Macromol 121: 1005-1010, 2019. PMID: 30342120. DOI: $10.1016 /$ j.ijbiomac.2018.10.117

29 Lin CP and Tsai SY: Differences in the moisture capacity and thermal stability of Tremella fuciformis polysaccharides obtained by various drying processes. Molecules 24(15): 2856, 2019. PMID: 31390802. DOI: 10.3390/molecules24152856

30 Chiang JH, Tsai FJ, Hsu YM, Yin MC, Chiu HY and Yang JS: Sensitivity of allyl isothiocyanate to induce apoptosis via ER stress and the mitochondrial pathway upon ROS production in colorectal adenocarcinoma cells. Oncol Rep 44(4): 1415-1424, 2020. PMID: 32700751. DOI: 10.3892/or.2020.7700

31 Huang L, Chen J, Quan J and Xiang D: Rosmarinic acid inhibits proliferation and migration, promotes apoptosis and enhances cisplatin sensitivity of melanoma cells through inhibiting ADAM17/EGFR/AKT/GSK3 $\beta$ axis. Bioengineered 12(1): 30653076, 2021. PMID: 34224305. DOI: 10.1080/21655979. 2021.1941699

32 Liu SP, Shibu MA, Tsai FJ, Hsu YM, Tsai CH, Chung JG, Yang JS, Tang CH, Wang S, Li Q and Huang CY: Tetramethylpyrazine reverses high-glucose induced hypoxic effects by negatively regulating HIF-1 $\alpha$ induced BNIP3 expression to ameliorate H9c2 cardiomyoblast apoptosis. Nutr Metab (Lond) 17: 12, 2020. PMID: 32021640. DOI: 10.1186/s12986-020-0432-x

33 Lu CC, Chiang JH, Tsai FJ, Hsu YM, Juan YN, Yang JS and Chiu HY: Metformin triggers the intrinsic apoptotic response in human AGS gastric adenocarcinoma cells by activating AMPK and suppressing mTOR/AKT signaling. Int J Oncol 54(4): 1271-1281, 2019. PMID: 30720062. DOI: 10.3892/ijo.2019.4704

34 Horng CT, Yang JS, Chiang JH, Lu CC, Lee CF, Chiang NN and Chen FA: Inhibitory effects of tetrandrine on epidermal growth factor-induced invasion and migration in HT29 human colorectal adenocarcinoma cells. Mol Med Rep 13(1): 1003-1009, 2016. PMID: 26648313. DOI: 10.3892/mmr.2015.4635

35 Lee HP, Wang SW, Wu YC, Tsai CH, Tsai FJ, Chung JG, Huang CY, Yang JS, Hsu YM, Yin MC, Li TM and Tang $\mathrm{CH}$ : Glucocerebroside reduces endothelial progenitor cell-induced angiogenesis. Food Agric Immunol 30(1): 1033-1045, 2019. DOI: $10.1080 / 09540105.2019 .1660623$

36 Lu CC, Yang JS, Chiu YJ, Tsai FJ, Hsu YM, Yin MC, Juan YN, Ho TJ and Chen HP: Dracorhodin perchlorate enhances wound healing via $\beta$-catenin, ERK/p38, and AKT signaling in human HaCaT keratinocytes. Exp Ther Med 22(2): 822, 2021. PMID: 34131445. DOI: 10.3892/etm.2021.10254

37 Lin CC, Chen KB, Tsai CH, Tsai FJ, Huang CY, Tang CH, Yang JS, Hsu YM, Peng SF and Chung JG: Casticin inhibits human prostate cancer DU 145 cell migration and invasion via Ras/Akt/NF-kB signaling pathways. J Food Biochem 43(7): e12902, 2019. PMID: 31353708. DOI: 10.1111/jfbc.12902 
38 Lee TH and Lee MS: Studies on MSH-induced melanogenesis: effect of long-term administration of MSH on the melanin content and tyrosinase activity. Endocrinology 88(1): 155-164, 1971. PMID: 4991823. DOI: 10.1210/endo-88-1-155

39 Wilczek A and Mishima Y: Inhibitory effects of melanin monomers, dihydroxyindole-2-carboxylic acid (DHICA) and dihydroxyindole (DHI) on mammalian tyrosinase, with a special reference to the role of DHICA/DHI ratio in melanogenesis. Pigment Cell Res 8(2): 105-112, 1995. PMID: 7659677. DOI: 10.1111/j.1600-0749.1995.tb00649.x

40 Hollinger JC, Angra K and Halder RM: Are natural ingredients effective in the management of hyperpigmentation? A systematic review. J Clin Aesthet Dermatol 11(2): 28-37, 2018. PMID: 29552273.

41 Hermann H: [Therapy of syphilis and certain skin diseases as reflected in the writings of Francisco Hernandez and Francisco Ximenez; a contribution on the history of dermatology in the 16th and $17^{\text {th }}$ centuries]. Medizinische (14): 527-530, 1956 PMID: 13321459.

42 Goldschmidt $\mathrm{H}$ and Raymond JZ: Quantitative analysis of skin color from melanin content of superficial skin cells. J Forensic Sci 17(1): 124-131, 1972. PMID: 4680739.

43 Magnin PH and Rothman S: Inhibition of melanin formation by human epidermis. Dermatologica 115(3): 315-320, 1957. PMID: 13480105. DOI: $10.1159 / 000256019$

44 Staricco RJ: Qualitative and quantitative data on melanocytes in human epidermis treated with thorium X. J Invest Dermatol 29(3): 185-195, 1957. PMID: 13481430. DOI: 10.1038/jid.1957.86

45 Staricco RJ and Pinkus H: Quantitative and qualitative data on the pigment cells of adult human epidermis. J Invest Dermatol 28(1): 33-45, 1957. PMID: 13416674. DOI: 10.1038/jid.1957.4

46 Iozumi K, Hoganson GE, Pennella R, Everett MA and Fuller $\mathrm{BB}$ : Role of tyrosinase as the determinant of pigmentation in cultured human melanocytes. J Invest Dermatol 100(6): 806-811, 1993. PMID: 8496620. DOI: 10.1111/1523-1747.ep12476630

47 Slominski A, Moellmann G and Kuklinska E: L-tyrosine, Ldopa, and tyrosinase as positive regulators of the subcellular apparatus of melanogenesis in Bomirski $\mathrm{Ab}$ amelanotic melanoma cells. Pigment Cell Res 2(2): 109-116, 1989. PMID: 2497448. DOI: 10.1111/j.1600-0749.1989.tb00170.x

48 Prezioso JA, Damodaran KM, Wang N and Bloomer WD: Mechanism(s) regulating inhibition of thymidylate synthase and growth by gamma-L-glutaminyl-4-hydroxy-3-iodobenzene, a novel melanin precursor, in melanogenic melanoma cells. Biochem Pharmacol 45(2): 473-481, 1993. PMID: 8435097. DOI: 10.1016/0006-2952(93)90085-b

49 Słominski A, Moellmann G, Kuklinska E, Bomirski A and Pawelek J: Positive regulation of melanin pigmentation by two key substrates of the melanogenic pathway, L-tyrosine and Ldopa. J Cell Sci 89 (Pt 3): 287-296, 1988. PMID: 3143738.

50 Cao J, Tyburczy ME, Moss J, Darling TN, Widlund HR and Kwiatkowski DJ: Tuberous sclerosis complex inactivation disrupts melanogenesis via mTORC1 activation. J Clin Invest 127(1): 349364, 2017. PMID: 27918305. DOI: 10.1172/JCI84262
51 Gaspar K, Kukova G, Bunemann E, Buhren BA, Sonkoly E, Szollosi AG, Muller A, Savinko T, Lauerma AI, Alenius H, Kemeny L, Dieu-Nosjean MC, Stander S, Fischer JW, Ruzicka T, Zlotnik A, Szegedi A and Homey B: The chemokine receptor CCR3 participates in tissue remodeling during atopic skin inflammation. J Dermatol Sci 71(1): 12-21, 2013. PMID: 23702389. DOI: $10.1016 /$ j.jdermsci.2013.04.011

52 Ivanov KP: [The conference on hematopoiesis and the physiological functions of the body's immune system]. Fiziol $\mathrm{Zh}$ Im I M Sechenova 81(9): 154-156, 1995. PMID: 8581049.

53 Shi LB, Zhang HW and Cui YY: [Implication of different expression of IL-2 mRNA and IL-10 mRNA in $\mathrm{CD} 4(+) \mathrm{CD} 25(+) \mathrm{T}$ cell induced immune tolerance of liver transplantation in rat]. Zhongguo Wei Zhong Bing Ji Jiu Yi Xue 20(5): 257-260, 2008. PMID: 18471351.

54 Guardiola FA, Bahi A, Jiménez-Monreal AM, Martínez-Tomé M, Murcia MA and Esteban MA: Dietary administration effects of fenugreek seeds on skin mucosal antioxidant and immunity status of gilthead seabream (Sparus aurata L.). Fish Shellfish Immunol 75: 357-364, 2018. PMID: 29462748. DOI: 10.1016/ j.fsi.2018.02.025

55 Giri SS, Sukumaran V and Park SC: Effects of bioactive substance from turmeric on growth, skin mucosal immunity and antioxidant factors in common carp, Cyprinus carpio. Fish Shellfish Immunol 92: 612-620, 2019. PMID: 31265909. DOI: 10.1016/j.fsi.2019.06.053

56 Shen T, Duan C, Chen B, Li M, Ruan Y, Xu D, Shi D, Yu D, Li $\mathrm{J}$ and Wang C: Tremella fuciformis polysaccharide suppresses hydrogen peroxide-triggered injury of human skin fibroblasts via upregulation of SIRT1. Mol Med Rep 16(2): 1340-1346, 2017. PMID: 28627707. DOI: 10.3892/mmr.2017.6754

57 Scharffetter-Kochanek K, Wlaschek M, Brenneisen P, Schauen $\mathrm{M}$, Blaudschun $\mathrm{R}$ and Wenk $\mathrm{J}$ : UV-induced reactive oxygen species in photocarcinogenesis and photoaging. Biol Chem 378(11): 1247-1257, 1997. PMID: 9426184.

58 Parkinson EK: Defective responses of transformed keratinocytes to terminal differentiation stimuli. Their role in epidermal tumour promotion by phorbol esters and by deep skin wounding. Br J Cancer 52(4): 479-493, 1985. PMID: 2415144. DOI: 10.1038/bjc. 1985.219

59 Najafi A, Adutwum E, Yari A, Salehi E, Mikaeili S, Dashtestani F, Abolhassani F, Rashki L, Shiasi S and Asadi E: Melatonin affects membrane integrity, intracellular reactive oxygen species, caspase 3 activity and AKT phosphorylation in frozen thawed human sperm. Cell Tissue Res 372(1): 149-159, 2018. PMID: 29196809. DOI: 10.1007/s00441-017-2743-4

60 Cooke JV, Goldring D and Kahn LI: The occurrence of changes resembling the inflammatory in skin injured and incubated after excision. J Exp Med 97(5): 651-662, 1953. PMID: 13052825. DOI: $10.1084 /$ jem.97.5.651

Received October 28, 2021

Revised December 8, 2021

Accepted December 9, 2021 